\title{
The Risk Management Process
}

Freddy Madsen, MSc

Civil Engineering, Tryg-Baltica Risk Management

The risk management process (Figure 1) is incorporated into a growing number of standards and guidelines. Japan, Canada, and Australia have adapted the process to prevent future disasters, or to be better prepared for the next ones. This paper addresses the risk management process in general, and subsequent topics such as:

- Transfer of risk information prior to accidents/disasters;

- The risk management process as the link between "ordinary" accidents and "disasters";

- Transformation of experience to knowledge; and

- Criteria for accepting risks.

Keywords: guidelines; risk, management of

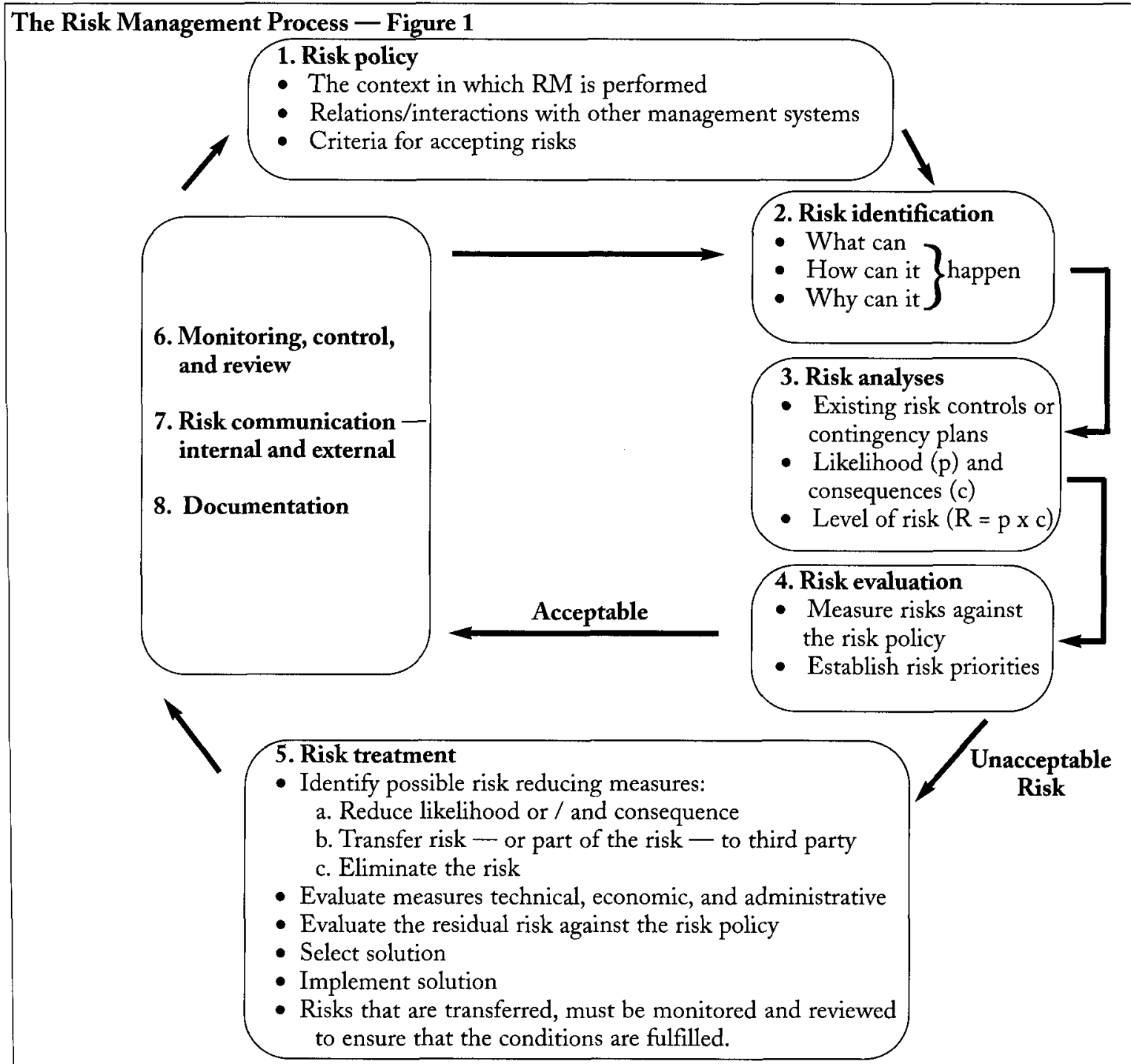

